\title{
Predictive Factors for Abnormal Brain CT-Scan in Childhood Epilepsy at Yaoundé (Cameroon)
}

\author{
Boniface Moifo ${ }^{1,3^{*}}$, Séraphin Nguefack ${ }^{2,3}$, Jean Roger Moulion Tapouh ${ }^{3}$, Evelyn Mah ${ }^{2,3}$, \\ Elie Mbonda ${ }^{2,3}$, Joseph Gonsu Fotsin ${ }^{1,3}$ \\ ${ }^{1}$ Department of Radiology and Medical Imaging, Yaoundé Gynaeco-Obstetrical and Pediatric Hospital (YGOPH), \\ Yaoundé, Cameroon \\ ${ }^{2}$ Department of Pediatrics and Subspecialties, Yaoundé Gynaeco-Obstetrical and Pediatric Hospital (YGOPH), \\ Yaoundé, Cameroon \\ ${ }^{3}$ Faculty of Medicine and Biomedical Sciences, The University of Yaoundé I, Yaoundé, Cameroon \\ Email: bmoifo@yahoo.fr, seraphin_nguefack@yahoo.fr, tapouh@yahoo.fr
}

Received 12 January 2014; revised 21 February 2014; accepted 3 March 2014

Copyright (C) 2014 by authors and Scientific Research Publishing Inc.

This work is licensed under the Creative Commons Attribution International License (CC BY).

http://creativecommons.org/licenses/by/4.0/

(c) (i) Open Access

\section{Abstract}

Purpose: Despite irradiation, CT-scan remains an important diagnostic tool in epilepsy in poor countries where MRI is neither available nor affordable. But many causes of epilepsy are not accessible to CT-scan and this technique remains expensive for many poor families in countries with limited resources. The aim of this study was to determine clinical or electroencephalogram variables which could predict brain CT-scan abnormalities in childhood epilepsy. Methods: It was a cross-sectional study including 151 epileptic children who underwent head CT-scan from October 2011 to march 2012, in one university-affiliated hospital in Cameroon (YGOPH). The data collected were clinical, type of seizure, Electroencephalogram and head CT-scans results. Independent predictive factors for CT abnormalities were sought by logistic regression. A p value $<0.05$ was considered. Results: Of the 151 children, $54.3 \%$ (82/151) were boys (sex ratio: $1.18 \mathrm{M} / 1 \mathrm{~F}$ ). The median age was 54 months [ 2 - 190 months]; $74.8 \%$ of children were more than 2 years old but at the onset of epilepsy they were 2 years old or less. Birth asphyxia, mental retardation and neurologic deficit were respectively associated in $62.4 \%, 54.3 \%$ and $51.7 \%$ of cases. Eighty-five had focal epilepsy (56.3\%), 61.6\% had abnormal head CT-scan, 68.9\% had abnormal EEG, with no significant gender difference. The factors most significantly associated with abnormal head CT-scan were: child age $\leq 2$ years, maternal hypertension/eclampsy, cerebral palsy, and child microcephaly, with $\mathbf{8 9 \%}$ to $\mathbf{9 2 \%}$ abnormal CT. The two independent predictors of abnormal CT were patients' age $\leq 2$ years and microcephaly. The two main CT-scan lesions were cerebral atrophy $\mathbf{2 8 . 5 \% )}$ and brain infarct (16.6\%). None of these abnormalities was correlated to any type of epi-

\footnotetext{
${ }^{*}$ Corresponding author.
} 
lepsy. Conclusion: Almost two-thirds of head CT-scan performed in epileptic children are abnormal in our setting. Patients of 2 years old or less and those with microcephaly are very likely to have brain anomalies on CT-scan. The most common brain lesions are atrophy, cerebral infarction and porencephalic cavities. Action to reduce birth asphyxia may lead to the reduction of the incidence of epilepsy in children.

\section{Keywords}

Epilepsy; Childhood; Electroencephalogram; CT-Scan; Predicting Factor; Microcephaly; Cameroon

\section{Introduction}

Epilepsy is a widespread disease with an incidence in children and adolescents ranging from 50 to 100/100,000 person-years across all populations over the world [1]. In 1995, Mbonda et al. found that, 1.85\% children consulting at the Yaoundé Centre Hospitals' emergency ward were epileptic [2]. Although epilepsy is a complex disease and often without organic cause, imaging is still indicated in some cases to search for potentially treatable lesions or which can explain a particular symptomatology.

Magnetic resonance imaging is the best imaging modality in this indication because it is very sensitive in the detection of brain pathology [3] with no radiation. Unfortunately, this is an expensive and poorly widespread technology especially in the sub-saharian countries. CT-scan is less sensitive than MRI but it is more widespread and more accessible. Despite radiation, CT-scan is reliable in the diagnosis of many diseases such as tumors, cerebral ischemia, some malformations and infections [4]-[6]. It is also ideal in the characterization of calcifications which can be suggestive of specific pathology. That is why the CT-scan is still an important diagnostic tool in epilepsy in poor countries where MRI is neither available nor affordable [7] [8]. Knowing that many causes of epilepsy are not accessible to CT-scan imaging and that this radiating technique remains expensive for many poor families in countries with limited resources, it is necessary to determine some criteria for selecting patients who more probably would have abnormal CT-scan examination.

Several studies have already been conducted to identify predictors of brain damage in case of seizures but very few focused specifically on pediatric epileptic population [8]-[17] and to the best of our knowledge, only two of them were carried out in sub-Saharan Africa [16] [17].

The aim of this study was to determine clinical or electroencephalogram variables which could predict brain CT-scan abnormalities in childhood epilepsy in our setting.

\section{Patients and Methods}

\subsection{Patients and Sampling}

From October 2011 to march 2012, all epileptic children who underwent a cerebral CT-scan in the Medical Imaging Service of the Yaoundé Gynaeco-Obstetric and Pediatric Hospital (YGOPH) were retrospectively enrolled for the purpose of this cross-sectional study. This university-affiliated hospital serves as a referral centre for neuropediatrics in Cameroon and throughout Central Africa. Patients with any acute inter-current condition possibly causative of seizures (trauma, known tumour, meningitis, septicaemia, encephalitis, embryo-fetopathies...) were excluded.

\subsection{Clinical Evaluation}

A complete clinical examination was performed by a neuropediatrician. The clinical data collected were age, sex, age of onset of seizures, neurological signs, frequency of seizures, head circumference, past medical history of the child (prenatal, perinatal and postnatal) including previous antiepileptic medication and outcome. Seizures were categorized as focal or generalized according to the International League Against Epilepsy classification [18].

\subsection{Paraclinical Assessment}

An Electroencephalogram (EEG) was performed in all the subjects using a 32-channel device from Micro- 
med-France. The setup used was consistent with the international 10/20 system with establishment of 10 or 21 electrodes according to the patient's age and head circumference. Intermittent photo-stimulation was performed in all patients. The EEG was analyzed by one neuropediatrician. The results were classified as normal or suggestive of focal or generalized epilepsy.

Unenhanced and when necessary enhanced helical head CT-scans of 3 to $5 \mathrm{~mm}$ thickness of all patients were reviewed by one pediatric radiologist and one general radiologist. They were classified as normal and abnormal CT-scan, with details on cerebral anomalies.

\subsection{Statistical Analysis}

Data analysis was performed using SPSS 20.0 (Chicago, USA.). Normality of the distribution was assessed with the Kolmogorov-Smirnov test. Proportions of normal and abnormal CT-scans among patients group were compared using chi-squared or Fisher test. Independent predictive factors for CT abnormalities were sought by logistic regression. A p value $<0.05$ was accepted to indicate statistical significance. The results are presented as count (proportions) and median (extreme values).

\section{Results}

The study included 151 children with 54.3\% (82/151) boys (sex ratio: $1.18 \mathrm{M} / 1 \mathrm{~F}$ ). The median age was 54 months [2 to 190 months]. Out of these children, 56.3\% (85/151) had focal epilepsy, and 61.6\% (93/151) had an abnormal brain CT (Table 1). There was no significant gender difference on the type of epilepsy $(p=0.32)$ or frequency of abnormalities in brain CT $(\mathrm{p}=0.36)$.

The majority of patients $(74.8 \%, 113 / 151)$ were age more than 2 years old but in $65.6 \%$ cases (99/151) epilepsy started when they were 2-year-old or less. Ninety-five children (62.9\%) experienced more than one seizure episode per day. Other frequent clinical findings were mental retardation (54.3\%) and neurologic deficit (51.7\%). Regarding past medical history, 64 children (62.4\%) had birth asphyxia and in 7.9\% (12/151) of cases there was a history of maternal hypertension or bleeding during pregnancy (Table 1).

Table 1. Clinical outcomes and correlation with brain CT results.

\begin{tabular}{|c|c|c|c|c|}
\hline Clinical data & Effective (\%) & Abnormal CT (\%*) & Normal CT (n) & p value \\
\hline $\begin{array}{c}\text { Type of epilepsy } \\
\text { Focal } \\
\text { Generalized }\end{array}$ & $\begin{array}{l}85(56.3) \\
66(43.7)\end{array}$ & $\begin{array}{l}46(54.1) \\
47(71.2)\end{array}$ & $\begin{array}{l}39 \\
19\end{array}$ & 0.02 \\
\hline $\begin{array}{l}\text { Patient's age } \\
\leq 2 \text { years } \\
>2 \text { years }\end{array}$ & $\begin{array}{c}38(25.2) \\
113(74.8)\end{array}$ & $\begin{array}{l}35 \text { (92.1) } \\
58(51.3)\end{array}$ & $\begin{array}{c}3 \\
55\end{array}$ & 0.00 \\
\hline $\begin{array}{l}\text { Age of the disease onset } \\
\qquad \begin{array}{l}\leq 1 \text { year } \\
>1 \text { year }\end{array}\end{array}$ & $\begin{array}{l}75(49.7) \\
76(50.3)\end{array}$ & $\begin{array}{c}60(80) \\
33(43.4)\end{array}$ & $\begin{array}{l}15 \\
43\end{array}$ & 0.00 \\
\hline Microcephaly & $37(24.5)$ & $33(\mathbf{8 9 . 2})$ & 4 & 0.00 \\
\hline Cerebral palsy & 33 (21.9) & 30 (90.9) & 3 & 0.00 \\
\hline $\begin{array}{l}\text { Frequency of seizures } \\
\quad>1 \text { day } \\
\leq 1 / \text { day }\end{array}$ & $\begin{array}{l}95(62.9) \\
56(37.1)\end{array}$ & $\begin{array}{l}50(52.6) \\
43(76.8)\end{array}$ & $\begin{array}{l}45 \\
13\end{array}$ & 0.002 \\
\hline Mental retardation & $82(54.3)$ & $67(81.7)$ & 15 & 0.00 \\
\hline Neurologic deficit & $78(51.7)$ & $65(83.3)$ & 13 & 0.00 \\
\hline Abnormal EEG & $104(68 ., 9)$ & $66(63.5)$ & 38 & 0.29 \\
\hline \multicolumn{5}{|l|}{ Obstetrical history } \\
\hline Maternal non-infectious disease & $12(7.9)$ & $11(91.7)$ & 1 & 0.02 \\
\hline Birth asphyxia & $64(42.4)$ & $49(76.6)$ & 15 & 0.00 \\
\hline History of complex febrile seizures & $43(28.5)$ & $27(62.8)$ & 16 & 0.5 \\
\hline Seizures refractory to medication & $40(26.5)$ & $30(75)$ & 10 & 0.03 \\
\hline
\end{tabular}

* proportion calculated per clinical outcome. 
An abnormal EEG was found in 68.9\% cases (104/151) with 16 hypsyarythmia (West Syndrome), 15 generalized epilepsies, 74 focal epilepsies. The main foci were temporal (17/74), frontal (13/74), occipital (10/74) and centro-temporal (7/74). At univariate analysis, different clinical and past medical data correlated with abnormal brain CT are listed in Table 1.

The factors most significantly and most frequently associated with abnormal head CT-scan were: patient age equal or less than 2 years, maternal non-infectious disease, cerebral palsy, and child microcephaly, with 89 to $92 \%$ abnormal CT.

At multivariate analysis, two independent predictors of abnormal CT were identified: patients' age equal or less than 2 years and microcephaly (Table 2).

The three main CT-scan lesions were cerebral atrophy (28.5\%), brain infarct (16.6\%) and porencephalic cavities (9.3\%). None of these abnormalities was correlated to any type of epilepsy (Table 3).

Sixty eight percent (17/25) of patients with brain infarct had a history of birth asphyxia, and this difference was statistically significant $(\mathrm{p}=0.00)$.

\section{Discussion}

We carried out this cross-sectional study to determine consistent variables which could predict abnormal cerebral CT among children with epilepsy in our setting. The incidence of abnormal scans was $61.9 \%$ occurring mainly in generalized epilepsy. Independent predictors of abnormal cerebral CT were patients' age equal or less than 2 years microcephaly. The most frequent CT abnormalities were cerebral atrophy, brain infarct and porencephalic cavities.

We have identified several factors significantly associated with CT anomalies. Many of them had been previously described by other authors (Table 4). In our study, a patient age equal or less than two years was an

Table 2. Independent CT abnormalities determinants provided by multinomial logistic regression.

\begin{tabular}{ccc}
\hline Determinant & Regression coefficient $(\boldsymbol{\beta})$ & p value \\
\hline Patient's age equal or less than 2 years & 5.4 & 0.02 \\
Microcephaly & 3.5 & 0.04 \\
\hline
\end{tabular}

Table 3. Cerebral CT scan findings.

\begin{tabular}{|c|c|c|c|c|}
\hline Abnormalities & Effective (\%) & Focal epilepsy & Generalized epilepsy & $\mathbf{p}$ \\
\hline Cerebral atrophy & $43(28.5 \%)$ & 20 & 23 & 0.08 \\
\hline Brain infract & $25(16.6 \%)$ & 16 & 9 & 0.26 \\
\hline Porencephalic cavities & $14(9.3 \%)$ & 6 & 8 & 0.21 \\
\hline Parenchymal calcifications & $10(6.6 \%)$ & 3 & 7 & 0.08 \\
\hline Hydrocephalus & $7(4.6 \%)$ & 4 & 3 & 0.63 \\
\hline Schizencephaly & $1(0.7 \%)$ & 0 & 1 & 0.43 \\
\hline Chronic empyema & $1(0.7 \%)$ & 1 & 0 & 0.56 \\
\hline
\end{tabular}

Table 4. Factors associated with CT abnormalities in other studies.

\begin{tabular}{|c|c|c|c|c|c|c|c|c|}
\hline \multirow{2}{*}{ Factors associated with abnormal CT } & \multicolumn{8}{|c|}{ Studies indicated by the fist author of the study ${ }^{*}$} \\
\hline & Ref [11] & Ref [19] & Ref [12] & Ref [17] & Ref [16] & Ref [20] & Ref [10] & $\operatorname{Ref}[15]$ \\
\hline Partial seizures & - & - & + & & + & + & + & \\
\hline History of birth asphyxia & & & & + & & & & \\
\hline Age of onset $\leq 1$ an & & & & + & & & & \\
\hline Neurologic deficit & + & & + & & + & + & & + \\
\hline Mental retardation & + & & & & & & & + \\
\hline Pre and perinatal risk factors & - & & & & & & & \\
\hline High frequency of seizures & + & + & & & & & & \\
\hline Abnormal EEG & & + & + & & & & + & \\
\hline Patients' age $<2$ ans & & + & & & & & & \\
\hline
\end{tabular}

+: association found; -: Association rejected; 'Ref = reference: Lagenstein et al. [11], Bautovich et al. [19], Yang et al. [12], Wammanda et al. [17], Obajimi et al. [16], Patel et al. [20], Bachman et al. [10], Kapoor et al. [15]. 
independent risk factor for having an abnormal CT. This result is consistent with those of Kapoor et al. who concluded that the incidence of intracranial structural lesions associated with epilepsy is relatively higher in the young than the older children [15]. Abnormal head circumference especially microcephaly was also an independent predictor of CT abnormalities. It makes sense in so far as this anomaly probably indicates an underlying lesion such as brain atrophy, itself associated with birth asphyxia and cerebral palsy.

Unlike what is widely reported, we found CT abnormalities more frequently in generalized epilepsies. Most previous studies have shown that CT abnormalities were more frequent in focal epilepsies [10] [12] [15] [16]. In 1986, Patel et al. found in a study of 115 children that only 6 over 57 brain CT-scans performed in children with generalized epilepsy were abnormal. They recommended that this investigation should not be a part of the routine work-up of children with generalized seizures [20]. In the studies of Patel (2013), and Yang (1979), included children had a high prevalence of neurologic deficits, which could justify the high frequency of CT lesions in focal seizures. Obajimi et al. found $74.4 \%$ of CT abnormalities in partial epilepsy (vs $50 \%$ in generalized epilepsy) among 103 epileptic children in Nigeria. But in their study, patients with suspected specific etiologies (trauma, infection, tumor suspicion...) were not excluded [16]. It should also be noticed that apart from the study of Patel et al. in 2013, all those which assessed CT lesions depending on the type of epilepsy did not use the most recent classification of the ILAE [18]. Although their results are consistent, these studies were carried out on heterogeneous samples. Thus it is possible in some cases, as we have found, that CT abnormalities being more frequent in generalized epilepsies. This is even more true since Lagenstein et al., unlike others, did not find any correlation between the frequency of CT abnormalities and type of epilepsy [11]. We believe that a reasonable doubt must be maintained on the relationship between generalized epilepsy and abnormal CT until studies based on the current classification of epilepsies are conducted with larger and homogeneous samples. In the order hand, MRI studies in the same population will probably lead to different results. Some obvious focal lesions on MRI are not detectable on CT-scan.

The incidence of abnormal CT in our study (61.9\%) was higher than in the most of previous reports where it was between $22 \%$ and 52\% [10] [12] [13] [15]-[17]. The only study which found a higher CT abnormalities incidence (68\%) than ours is that of Patel et al. (2013) who worked on a very selective symptomatic sample of 59 children with predominantly focal motor-partial epilepsy in India [6]. Our patients were referred to the radiology department by experienced neuro-pediatricians who were sorting the patients initially by clinical examination and EEG. They used to request head CT-scan in case of generalized epilepsy when there were associated clinical factors or past history highly suggestive of brain lesion such as: cerebral palsy, microcephaly, birth asphyxia, severe mental retardation, suspicion of syndromic epilepsy... Secondly, in a country with limited resources like ours, poor families pay the exams only when they consider the disease as severe enough to justify supplementary expenditure. These two parameters have probably induced a selection bias justifying the high rate of abnormal CT in our study. The third consideration is about high population of cerebral palsy in our sample (33/151) with known high incidence of cerebral abnormalities on CT-scan [6], and the high population of microcephaly (37/151).

The most frequent CT abnormalities were cerebral atrophy, brain infarct and porencephalic cavities. These stable lesions also predominate in most previous studies carried out abroad [10] [12] [13] [17] and in our country [5] [6] [21]. In their screening of 100 children with epilepsy aged 0-3 years Kapoor et al. found that brain atrophy (9 case/24 abnormal CT) was the most common lesion. They estimated that brain atrophy seemed to be an important cause of epilepsy and that intracranial static and developmental anomalies are the most important cause of epilepsy in children specially infants and young ones [15]. Static processes like brain atrophy are untreatable, but their demonstration may be quite helpful to the family for the diagnosis' acceptance and to the physician in planning the care of children with chronic seizure disorders [10].

Cerebral infarct was another common lesion. We found that it was mainly due to birth asphyxia. In Nigeria, Wammanda et al. found that $90 \%$ of children who had abnormal CT-scan had significant past medical history with histories suggestive of birth asphyxia and cerebral infections [17]. This means that with good obstetric practice, many cases of epilepsy could be avoided in our setting where Moifo et al. [6] found $37.8 \%$ of epilepsy and $45.4 \%$ anoxo-ischemic-like hypodensities in cerebral palsy children, and Nguefack et al. found $41.8 \%$ anoxo-ischemic causes of developmental delay in children [21], and 55.9\% of birth asphyxia in West syndrome [5]. According to Adhikari et al., central nervous system infections are the main cause of seizures and acquired epilepsy in the developing countries [1]. Neurocysticercosis and neurotuberculosis are cited as common causes of epilepsy in tropical countries and particularly in India [8] [15]. But in a study conducted in Cameroon in 1998, 
Dongmo et al. compared 93 epileptic patients with 174 control subjects in an area of high endemicity of neurocysticercosis. They did not find any correlation between high serology for cysticercosis and epilepsy [22]. Unlike some authors who have conducted their studies in tropical areas [8] [9], we found no signs of active infectious lesions. This may be due to the fact that we excluded from our study children who had obvious clinical signs of infection in order to be sure to avoid non-epileptic causes of seizures. Other authors did not take the same precautions.

As limitations of this study, CT-scan although increasingly widespread is expensive for many families in our country, which probably created a selection bias in our sampling. However, to our knowledge, this study is the first of its kind conducted in a country of sub-Saharan Africa. In addition, unlike most other authors, we performed statistical tests to eliminate confounding factors and come to identify variables that predict the CT abnormalities independently. These predictors should be tested on a larger sample in order to verify their reliability.

\section{Conclusion}

At the Yaoundé Gynaeco-Obstetric and Pediatric Hospital, 61.9\% of brain CT performed in epileptic children are abnormal. The CT abnormalities are more common in generalized epilepsy. Patients aged 2 years or less and those with abnormal head circumference are very likely to have brain anomalies on CT-scan. The most common brain lesions are atrophy, cerebral infarction and porencephalic cavities. Action to reduce perinatal asphyxia may lead to the reduction of the incidence of epilepsy in children.

\section{Conflicts of Interests}

The authors declare none.

\section{Authors' Contributions}

BM, SN and MTJR conceived the study. SN, BM and EM collected the data. MTJR and BM co-analysed the data. MTJR and BM drafted the manuscript. JGF and EB supervised the data collection and critically revised the manuscript. All authors have read and approved the final manuscript.

\section{References}

[1] Adhikari, S., Sathian, B., Koirala, D.P. and Rao, K.S. (2013) Profile of Children Admitted with Seizures in a Tertiary Care Hospital of Western Nepal. BMC Pediatrics, 13, 43.

[2] Mbonda, E., Dongmo, L., Tietche, F., Motso, C., Mefo, S., Poka, D., et al. (1995) Aspects Cliniques et étiologiques de l'épilepsie du nourrisson et de l'enfant à Yaounde. Médecine d'Afrique Noire, 45, 286-290.

[3] Wilden, J.A. and Cohen-Gadol, A.A. (2012) Evaluation of First Nonfebrile Seizures. American Family Physician, 86, 334-340.

[4] Moifo, B., Nguefack, S., Neossi Guena, M., Mah, E., Guegang Goudjou, E., Mbonda, E., et al. (2012) Clinical and CT-Scan Presentations in Tuberous Sclerosis Complex: Report of Eight Pediatric Cases Revealed by Epilepsy. Mali Médical, 27, 51-56.

[5] Nguefack, S., Moifo, B., Chiabi, A., Defo, A.L., Mah, E., Fru, F., et al. (2013) Clinical, Aetiological and Evolutive Aspects of West Syndrome in Yaounde (Cameroon). Open Journal of Pediatrics, 03, 306-310. http://dx.doi.org/10.4236/ojped.2013.34055

[6] Moifo, B., Nguefack, S., Obi, F., Tambe, J., Mah, E., Mbonda, E., et al. (2013) Computed Tomography Findings in Cerebral Palsy in Yaounde-Cameroon. Journal Africain d'Imagerie Médicale, 5, 134-142.

[7] Grévent, D., Calmon, R., Brunelle, F. and Boddaert, N. (2012) Brain Imaging in Seizures. Revue du Praticien, 62, 1391-1394.

[8] Patel, N.H., Jain, A.R., Iyer, V.K., Shah, A.G., Jain, D.A. and Shah, A.A. (2013) Clinico—Diagnostic and Therapeutic Relevance of Computed Tomography Scan of Brain in Children with Partial Seizures. Annals of Indian Academy of Neurology, 16, 352-356. http://dx.doi.org/10.4103/0972-2327.116928

[9] Nair, K.P., Jayakumar, P.N., Taly, A.B., Arunodya, G.R., Swamy, H.S. and Shanmugam, V. (1997) CT in Simple Partial Seizures in Children: A Clinical and Computed Tomography Study. Acta Neurologica Scandinavica, 95, 197-200.

[10] Bachman, D.S., Hodges, F.J. and Freeman, J.M. (1976) Computerized Axial Tomography in Chronic Seizure Disorders of Childhood. Pediatrics, 58, 828-832. 
[11] Lagenstein, I., Sternowsky, H.J., Rothe, M., Bentele, K.H. and Kühne, G. (1980) CT in Different Epilepsies with Grand Mal and Focal Seizures in 309 Children: Relation to Clinical and Electroencephalographic Data. Neuropediatrics, 11, 323-338. http://dx.doi.org/10.1055/s-2008-1071400

[12] Yang, P.J., Berger, P.E., Cohen, M.E. and Duffner, P.K. (1979) Computed Tomography and Childhood Seizure Disorders. Neurology, 29, 1084-1088. http://dx.doi.org/10.1212/WNL.29.8.1084

[13] Minford, A.M. and Forsythe, W.I. (1992) Computed Tomography Findings in Partial Seizures. Archives of Disease in Childhood, 67, 693-696. http://dx.doi.org/10.1136/adc.67.6.693

[14] Gibbs, J., Appleton, R.E., Carty, H., Beirne, M. and Acomb, B.A. (1993) Focal Electroencephalographic Abnormalities and Computerised Tomography Findings in Children with Seizures. Journal of Neurology, Neurosurgery \& Psychiatry, 56, 369-371. http://dx.doi.org/10.1136/jnnp.56.4.369

[15] Kapoor, M., Talukdar, B., Chowdhury, V., Puri, V. and Rath, B. (1998) Intracranial Structural Lesions in Young Epileptics: A Computed Tomographic Study. Indian Pediatrics, 35, 537-541.

[16] Obajimi, M.O., Fatunde, O.J., Ogunseyinde, A.O., Omigbodun, O.O., Atalabi, O.M. and Joel, R.U. (2004) Computed Tomography and Childhood Seizure Disorder in Ibadan. West African Journal of Medicine, 23, 167-172. http://dx.doi.org/10.4314/wajm.v23i2.28112

[17] Wammanda, R.D., Anyiam, J.O., Hamidu, A.U., Chom, N.D. and Eseigbe, E.E. (2009) Computerized Tomography of Children with Seizure Disorders. Nigerian Journal of Clinical Practice, 12, 25-28.

[18] Berg, A.T., Berkovic, S.F., Brodie, M.J., Buchhalter, J., Cross, J.J.H., van Emde Boas, W., et al. (2010) Revised Terminology and Concepts for Organization of Seizures and Epilepsies: Report of the ILAE Commission on Classification and Terminology, 2005-2009. Epilepsia, 51, 676-685. http://dx.doi.org/10.1111/j.1528-1167.2010.02522.x

[19] Bautovich, T. and Numa, A. (2012) Role of Head Computed Tomography in the Evaluation of Children Admitted to the Paediatric Intensive Care Unit with New-Onset Seizure. Emergency Medicine Australasia, 24, 313-320. http://dx.doi.org/10.1111/j.1742-6723.2012.01561.x

[20] Patel, P.J., Kolawole, T.M., Mahdi, A.H. and Qteishat, W.A. (1986) Computed Tomography (CT) Scan Findings in Children with Seizures Only. Acta Neurologica Scandinavica, 74, 165-166. http://dx.doi.org/10.1111/j.1600-0404.1986.tb04645.x

[21] Nguefack, S., Kamga, K.K., Moifo, B., Chiabi, A., Mah, E. and Mbonda, E. (2013) Causes of Developmental Delay in Children of 5 to 72 Months Old at the Child Neurology Unit of Yaounde Gynaeco-Obstetric and Paediatric Hospital (Cameroon). Open Journal of Pediatrics, 03, 279-285. http://dx.doi.org/10.4236/ojped.2013.33050

[22] Dongmo, L., Druet-Cabanac, M., Moyou, S.R., Zebaze, D.R.M., Njamnshi, A.K., Sini, V., et al. (2004) Cysticercosis and Epilepsy: A Case-Control Study in Mbam Valley, Cameroon. Bulletin de la Société de Pathologie Exotique, 97, 105-108. 